\title{
Research on China's energy poverty evaluation framework based on Capabilities theory
}

\author{
Linlin Liang* \\ International Business School \\ Yunnan University of Finance and Economics \\ Kunming, China \\ 279653205@qq.com
}

\author{
Qicheng Lu \\ Business School \\ Yunnan University of Finance and Economics \\ Kunming, China \\ 317404322@qq.com
}

\begin{abstract}
With the rapid development of economy and society around the world, energy poverty is widespread around the world as one of the three major challenges of the world energy system, especially in developing countries, and has a serious impact on social life. This paper firstly reviews the energy poverty and the application of Capabilities theory and then constructs an evaluation framework of China's energy poverty based on Capabilities theory. This paper expands the understanding of multidimensionality of energy poverty, and provides a systematic and feasible energy poverty identification framework.
\end{abstract}

Keywords-energy poverty; Evaluation framework; Capabilities theory

\section{INTRODUCTION}

Energy is necessary for human being existence and social development as an important driving force [1]. However, persistent energy poverty, increasing energy supply disruption risk, environmental threat caused by energy production and use has formed the three big challenges of the global energy system. International energy agency (IEA) [2] drew a statistical conclusion in 2013 that there are 1.3 billion people worldwide without access to electricity, 2.6 billion people rely on traditional biomass for cooking activity, while with $95 \%$ of these people in Asia and Africa. Meanwhile, IEA predicts that 1 billion people will not be able to access electricity and 2.6 billion people will not be able to access clean cooking fuel by 2030.

As a developing country, the problem of energy poverty has been constraining the development of China's social economy and national welfare. There are about 423 million people relying on traditional biomass energy in China. The World Health Organization (WHO) data shows that the soot from cooking stoves in China's rural areas are responsible for the premature death of 300, 000 people a year. Kang Li etc.[3] found that rural families rely on traditional biomass for cooking activities in 21 provinces of China, and the traditional biomass of 6 provinces is more than $80 \%$. Especially in the rural areas in our country, traditional biomass energy is the main life [4], and presents a trend of increasing per capita consumption of this year. China's rural traditional biomass energy consumption accounts for about life can use $64.3 \%$ of the total in 2011 .
In 2015, the United Nations proposed and unanimously adopted the sustainable development goals for the next 15 years with 17 specific goals, including the elimination of any form of poverty globally; ensuring safe, healthy water and sanitation for all; ensuring sustainable energy supply; construct a sustainable consumption mode and the mode of production, etc.. These goals are not only closely related to energy poverty but also provide the necessary policy support to eliminate energy poverty. The United Nations development programme (UNDP) also provides countries with a convenient energy assessment technology and financial support. The assessment is mainly focused on poverty alleviation projects of each region of UNDP, the purpose is to let each country to realize mutual influence between energy supply and demand services and poverty alleviation, but also for countries to give advice to help them get affordable, convenient and reliable in use of modern energy services.

Our government has also been launched various measures of eliminating energy poverty policy, such as in 1999, the government began to promote the reform of rural electricity management system, transformation of rural power grid and realize urban and rural power network with the same price. In order to better meet the new development needs of the rural areas, the problem of rural power grid transformation was solved thoroughly, and a new round of agricultural net renovation was launched in 2010. In 2013, Inner Mongolia Province was powered by electricity from the power grid, wind and solar power was added to the "household electricity" project which enabled all electricity in the autonomous region. Natural gas pipe network construction project in outlying provinces provided a modern clean fuel, local residents over the history of the local burn wood to cook and raised the residents' quality of life [5].

After the elimination of all forms of energy poverty policies and measures, as to the inhabitants of our country, there are still a lot of difficult to obtain plenty of modern energy services to meet the demand for energy in their daily lives. In rural energy consumption of China, solid energy accounted for $74.9 \%$ among the rural consumer goods in 2011, the proportion fell to $54.8 \%$ by 2016 . Although the commodity consumption structure of rural life of solid energy accounted a downward trend, solid energy has yet to rural areas the main energy of life. Li kang, et al. [6] found in the research of China's energy poverty that northeast, southwest

* Corresponding author 
and northwest of energy poverty composite index is in steady decline from 2000 to 2003 and since 2008. But in 2004-2007, small fluctuations appeared. The overall index of energy poverty in the east coast continued to decline before 2008, however there has seen a slight rise since 2009. According to preliminary statistics from the national electricity administration, there will be 256 non-electric townships, 3,817 non-electric villages and 93.6 in July 2012.

We should firstly know energy poverty through accurately identifying energy poverty group to control energy poverty. It involves two problems, one is the connotation of energy poverty. That is what perspective we analyze energy poverty from. Second is the way energy poverty is assessed, that is how to judge energy poverty.

Amartya Sen's Capabilities theory allow us not just confined to the pure economic perspective to measure social welfare of the people, but give full consideration to the development of human freedom. Capabilities theory has been widely recognized and was applied to the research of welfare. The United Nations Development program (UNDP) adopted the definition of poverty based on Capabilities theory. It is thought that what we should focus on is not what people have or lack, but they can or can't do. The sum of the most basic income is not a measure of welfare, poverty means not only insufficient income, but the deny to basic development.

Based on this, this paper will redefine energy poverty based on Capabilities theory and analyze energy poverty to stimulate to new understanding of energy poverty. This research provides new ideas for evaluation, and founds a basis for eliminating energy poverty and poverty reduction policy.

\section{THEORETICAL FOUNDATION}

\section{A. Main contents of Capabilities theory}

\section{1) Functionings}

Amartya Sen believes that a person's welfare can be assessed from the situation of his life. The need to view life as a combination of all functional activities means that the implementation of various activities constitutes a person's life situation. It is also said that functional activity reflects a variety of things or states that a person thinks is worth doing or achieving. Unlike resources and income, functionings are substantial, while income or resources carry out the means of the functional activity or tool.

\section{2) Transforming factors}

Conversion from resources into functional activities are in the control of transforming factors. There are five sources: individual heterogeneity, diversity of environment, difference between social atmosphere, difference in relationships, domestic distribution.

\section{B. Energy poverty in evaluation framework}

According to Capabilities theory, development is the process of expanding freedom and the ultimate goal is to achieve "substantial freedom". Capabilities are the combination of various functional activities which can be realized by people, the size of the feasible capabilities set reflects the category of freedom what people really have, so development can also be seen as viable capabilities set extension. There is an important link between energy poverty and practicability, and the capabilities to do so is not directly or indirectly contributing to energy poverty. From the perspective of Capabilities, the features of energy consumption is a transformational factor that affects the transition from the endowments to the actual functional activities that can be achieved.

Therefore, the article gives a definition of energy poverty is: because the family can use such as energy level characteristics caused by the missing part of the basic functional activities, thus forming "stripped" practical ability, called energy poverty. Assessment of energy poverty through measurement and energy acquisition and use of related functional activities.

\section{CONSTRUCTION OF ENERGY POVERTY EVALUATION FRAMEWORK}

\section{A. Description of evaluation framework based on Capabilities theory}

In the practical application of Capabilities, we need to solve two methodological problems. The first one is the choice of related functions. Amartya Sen pointed out that, Evaluation is unavoidable when screening function and ability of the corresponding description. Now that we have to choose, it will certainly have a focus. In other words, some function is very important, some function is not important and can be ignored. Amartya Sen affirmed five key instrumental freedoms, such as the economic opportunities, political freedom, social conditions, transparency, assurance, to guarantee protective role in the study of welfare. It is thought that these different types of power and opportunity respectively promote their practical ability, the theory also discussed a person's general and discusses the connection between the instrumental freedom. In actual research, the question of how to choose the relevant function is determined by the researchers' values, and there is no consensus in the theoretical world. Based on energy poverty research, this paper combined the practical ability with choosing the economic opportunities, living conditions and health condition, social opportunities, protective security five features, analysis of energy poverty. Second is the measurement of functional capability at the individual level, which includes how to assign the functions that have been implemented and how to measure individual benefits by combining the functional assembly index.

\section{1) Economic opportunity}

Amartya Sen to economic opportunity, as one of the instrumental freedom, and defined as an individual to use its economic resources and consumption, production, or exchange opportunities. Although we do not agree with pure energy consumption of the poor economy as an energy source to measure energy poverty in the poverty line, but does not negate the deprivation of the feasible ability usually has close relationship with low income, poor economic and energy must connect with each other, because income is so important for a feasible ability means, low-income both hunger and 
nutritional deficiencies, and illiteracy and one of the major causes of ill health, whereas a better education is helpful to obtain higher income. And since, improve the practical ability of enjoy life generally will be extended to make people more productive and earn higher incomes, there we can expect from the practical ability to improve to the greater earning ability, such a connection, two not only one-way links from income to practical ability.

Sara (2001) argue that family economic resources can reflect the social status of family members, whether their goods and services available as well as feel safe after emergency subjective feeling can also reflect the comfort of family life. Amartya Sen also believes that in the study of poverty, any information on income distribution can be used as a starting point for the study of poverty. So households' willingness to spend on energy reflects whether the family has the financial capacity to maintain a sense of subjective security and comfort [6]. High energy costs deprive some families of obtaining and using energy economic resources consumption or exchange opportunities, namely family economic opportunity deprivation. Or the family voluntarily reduce energy expenditure in order to maintain other necessary consumption and make it impossible to maintain the comfort of family life, thereby depriving the living opportunity.

\section{2) Living opportunity}

Before the International Energy Agency put forward the definition of energy poverty, Lewis proposed energy poverty is unable to maintain sufficient warm home. Robeyns also thought that a good living condition is closely related to from instrumental perspective. Bratt (2002) argues that housing is actually a resident status symbol, which often has a substantial impact on the individual psychology. Energy consumption determined the temperature, humidity, and indoor air quality of a building, and equipments such as refrigerators, freezers determined the diversity of food and food quality etc., these indexes influenced even decided to the most basic human rights and freedom - survive without premature death. Therefore, this paper selects the family housing opportunity to study the functional activities of energy poverty. Living opportunity also directly affect residents' health conditions, appropriate temperature, humidity and good air quality and contribute to a healthy residents. A wide range of high quality things also contributed to a healthy person's full scale development.

\section{3) Physical condition}

The international energy agency predicted in 2010 that the death toll from IAP (indoor environmental pollution) is expected to be greater than malaria, tuberculosis and HIV by 2030. Indoor chemical pollutants and the harm of chemical pollutants including formaldehyde, benzene, toluene and xylene, volatile organic compounds and ammonia, carbon monoxide, carbon dioxide, sulphur dioxide, formaldehyde, benzene and ammonia is one of the main indoor air pollutants. And, the IAP is not the only health consequence of energy poverty, and there is a risk involved in gathering fuel.

Long-term exposure to indoor air pollution is easy to infected by respiratory system diseases such as bronchitis and lung cancer(WHO, 2002). According to The global burden of disease study group (GBD) data published in The Lancet in 2010 , China has a population of 2010 of indoor air pollution caused by solid fuel use and premature deaths $(12.5 \%$ of The national premature deaths). This is roughly equivalent to the premature death toll from outdoor air particulates (1.23 million). Given this, energy poverty will have a huge impact on people's health. Good health condition could guarantee social opportunity and a sound health were more likely to activity on a larger scale.

\section{4) Social opportunity}

Social opportunities mainly refer to social arrangements in education, health care, etc., and they affect the individual's return to a better life. Social opportunities are closely related to economic opportunity and political participation. Taking education as an example, Illiteracy is a huge obstacle for people to the specifications production or economic activity to strict quality management, and a person who won't read a newspaper or contact with other people is also a kind of restriction to participate in political activities written for political participation [7]. Oscar Lewis explain the reason for the poor from social cultural perspective. And it is thought that the responsibility of the poverty is due to poor living habits, living patterns, and the uniqueness of this prompted the poor tend to be more frequent interactions, thus cut off from contact with other social strata, belong to the poor class poor subculture. This subculture is reinforced and institutionalized within the poor. Although the theory excessively exaggerated the role of the culture in produce process, but there is no denying that the lack of cultural and other social opportunities is not only the causes of poverty, but also the result of poverty.

As education level and working conditions may limit the choice of household energy use, at the same time, the personnel engaged in major domestic service isdue to the education level and its limited use efficient clean energy. Although women prefer clean, healthy cooking fuel and stoves, they do not usually choose to buy decision-making power. In the use of traditional biomass for the main energy in the family, energy for work - acquisition and processing, mainly by women and children, and thus affect children knowledge time acquisition, and compressed the women's leisure, social, the opportunity to work with time. Simon Wagura Ndiritu et al., [8] found from a study in Kenya that $41 \%$ of 5-18 children collect wood more than 2.5 hours, and when the children spend time on gathering sleep and natural wood more than 2 hours, the possibility of admission will be reduced by $21 \%$.

\section{5) Affordable protection}

Energy poverty policy of China fall into four categories, modern energy availability and affordable policy (such as guarantee rural electricity supply through the rural power grid construction, accelerate the promotion of natural gas application in order to improve the availability of clean fuel, fossil energy subsidies or subsidies for residents to improve the energy affordable goods, etc.), improve the efficiency of household energy policy, improve the efficiency of household energy mainly from collective instead of distributed heating for heating, building heat preservation and energy saving 
transformation, etc.), promote development and utilization of renewable energy policy (e.g., vigorously develop the rural biogas construction) and other energy poverty policy response.

More and better safeguards will also reduce the amount of energy that residents spend on energy, thereby guaranteeing their economic opportunities. Better education and health care can not only improve quality of life, but also improve access to income and escape income poverty. The spread of education and health care made those who would otherwise be poor get better access to customer service. Energy subsidies can make it more likely that people will be able to choose efficient energy sources, and improve the energy infrastructure to ensure that people choose and use energy.

\section{B. Initial model building}

According to the index system described in last chapter, economic opportunity, chance, healthy living, social opportunities, protective security are the latent variables in the structural equation model. Family can use characteristics as latent variables and use descriptive indicators of the latent variables as its observation. According to the Capabilities theory, each structural latent variable is taken as the five functional activities, which together constitute the Capabilities set. Therefore, Capabilities is the second order latent variable.

\section{CONCLUSION}

From the perspective of Capabilities theory, the paper builds theoretical energy poverty evaluation framework through the reconstruction of the evaluation space and evaluation method of energy poverty. First of all, this paper selected energy related economic conditions, living conditions, health, social opportunities, protective security as the basic functional activities to build energy poverty evaluation space. Due to the five indicators of functional activities can not directly be gotten, so this paper selected each functional activities from three to four descriptive indicators, among which the economic opportunities was represented with annual per capita income, source of income, per capita annual expenditure, per capita energy expenditure description; Housing type was represented with room temperature, winter room temperature, clean energy equipment description; Health conditions were described by accident injuries, respiratory systems, cardiopulmonary system, and nutritional status; The social opportunity was described with the household owner education level, the adolescents affected by education status, the work status of the kitchen staff, the information source description; Protection is guaranteed by energy subsidies, energy selectivity, and energy infrastructure satisfaction.

\section{ACKNOWLEDGMENT}

The authors thank other members of the research group for helpful, valuable, and constructive comments and suggestions on earlier versions of this paper. The paper is supported by the National Natural Science Foundation of China (No.71663057).

\section{REFERENCES}

[1] F. Birol, "Energy Economics: A Place for Energy Poverty in the Agenda?" The Energy Journal, 2007, pp. 1-6.

[2] IEA (International Energy Agency). World Energy Outlook 2013, IEA.

[3] L. Kang, C.F. Liu, Y.M. Wei, "Analysis of the current situation of energy poverty in China," China energy, vol. 33, pp. 31-35, August 2011.

[4] Y.M. Wei, H. Liao, and K. Wang, "China energy report (2014):Energy poverty," Science Press:Beijing, 2014, pp. 45-48.

[5] M.J. Li, L.W. Wang, and Z.F. Mi, "China's policies and actions to eliminate energy poverty," China energy, 2014, pp. 40-43.

[6] K. Li, K. Wang, and Y.X. Wang, "Comprehensive evaluation of energy poverty in China," Journal of the Beijing institute of technology(social science edition), pp.1-12, June 2014.

[7] S.Lelli, "Factor Analysis vs. Fuzzy Sets Theory: Assessing the Influence of Different Techniques on Sen's Functioning Approach," Center for Economic Studies Discussions Paper Series (DPS) 2011.

[8] S.W. Ndiritu, and W. Nyangena, "Environmental Goods Collection and Children's Schooling: Evidence from Kenya," Environment for Development Discussion Paper Series 2010. 